re-attachment of the retina can now be achieved in a high percentage of cases. It is to be hoped that in future symposia of this type we shall be equally encouraged by the functional results that at present elude us in so many cases.

Any surgeon interested in the treatment of retinal detachments will find much stimulating material in this volume.

Précis d'ophtalmologie. By H. Saraux and B. Biais. 1969. Pp. 978, 528 figs, 3 col. pl., bibl. Masson, Paris. (NEI50)

This new textbook of ophthalmology is divided into six parts: methods of examination, diseases of the eye and adnexa, neuro-ophthalmology, the eye and general disease, trauma, and therapy. The subject is covered succinctly and in an up-to-date manner and is suitable for the junior ophthalmologist requiring a textbook in French. The illustrations vary considerably in quality and there are several misprints in the text. In spite of these minor criticisms, which it is hoped will be corrected in future editions, this book is a useful addition to French ophthalmic literature.

\title{
Proceedings of the Centennial Symposium, Manhattan Eye, Ear, and Throat
} Hospital. Vol. I. Ophthalmology. Edited by A. I. Turtz. I969. Pp. 33 I, 247 figs, refs. Mosby, St. Louis; Kimpton, London. (247s.)

This symposium was designed in honour of the Centennial Anniversary of the Manhattan Eye, Ear and Throat Hospital, supported by financial grants from two foundations. The book, which is rather expensive, although it is most successful in giving authoritative views on many of the chief growing points in our subject, is divided into six sections: (I) New concepts in ocular therapy, (2) Controversial areas in ocular surgery, (3) Paediatric ophthalmic problems, (4) Ophthalmic plastic surgery, (5) New techniques in ophthalmology, (6) Complications in ocular surgery.

The 32 subsections naturally vary in quality and detail, but they are of special value in keeping the general ophthalmic surgeon abreast of recent developments, and the specialist in touch with fields other than his own.

The symposium was obviously planned with imagination and intelligence, and is a credit not only to the participants but also to the great hospital which it was called to honour.

Parson's Diseases of the Eye. I $5^{\text {th }}$ ed. By S. Duke-Elder. I969. Pp. 597, 453 figs, 2 I col. pl. Churchill, London. (75s.)

The publication of the $15^{\text {th }}$ edition of this work is in itself a tribute to its continuing and well-deserved popularity. Short of being a text-book, it provides a comprehensive and lucid guide to practically the whole field of ophthalmology. It is most useful perhaps to ophthalmic house-surgeons, especially to those aspiring to ophthalmology as a career, who will find therein a basic guide to the first principles of approach and basic information on a very wide range of ocular malfunction and disease. It is equally valuable as a source of reference to casualty officers, general practitioners, and, indeed, to any who wish a concise and clear exposition of some problem or disease with which they are not familiar.

This new edition, appearing some 5 years after its predecessor, has been extensively amended to keep up to date with current trends and developments, particularly perhaps in the field of the various retinopathies, and equally successfully elsewhere.

The production is well up to the high standard we have come to expect of its publishers, who surely must also be warmly complimented on having been able to keep the price within such reasonable bounds. The paper-back E.L.B.S. (English Language Book Society) edition at $35^{s}$. ( $£$ I.75 decimal), while obviously not so durable for library use, is a quite outstanding bargain. 